Abstract 103 Table 1 Vital capacity of athletes, singers and non athlete non singers

\begin{tabular}{|c|c|c|c|c|c|c|c|c|c|c|}
\hline & \multicolumn{2}{|c|}{ Group A } & \multicolumn{2}{|c|}{$\begin{array}{l}\text { Group } \\
\text { Non AS }\end{array}$} & \multirow[t]{2}{*}{$p$ value } & \multicolumn{2}{|c|}{ Group S } & \multicolumn{2}{|c|}{ Group Non AS } & \multirow[t]{2}{*}{$p$ value } \\
\hline & Mean & $\pm \mathrm{SD}$ & Mean & $\pm \mathrm{SD}$ & & Mean & $\pm S D$ & Mean & \pm SD & \\
\hline Vital Capacity(ml) & 3452.5 & 696.7 & 2625 & 543.74 & $0.0002^{*}$ & 3015 & 346.83 & 2625 & 543.74 & 0.01 * \\
\hline
\end{tabular}

\begin{tabular}{|c|c|c|c|c|c|}
\hline & \multicolumn{2}{|c|}{ Unstandardized Coefficients } & \multirow[t]{2}{*}{$P$ value } & \multicolumn{2}{|c|}{$95 \%$ Confidence interval for B } \\
\hline & B & Std. Error & & Lower Bound & Upper Bound \\
\hline Age (yrs) & 205.000 & 174.025 & .244 & -143.349 & 553.349 \\
\hline Height & 36.450 & 16.800 & .034 & 2.821 & 70.079 \\
\hline Weight & -16.297 & 13.464 & .231 & -43.248 & 10.654 \\
\hline Overweight & -245.833 & 166.344 & .145 & -578.807 & 87.140 \\
\hline \multicolumn{6}{|l|}{ Group } \\
\hline \multicolumn{6}{|l|}{ Non AS } \\
\hline Athletes & 827.500 & 197.617 & .0002 & 427.446 & 1227.554 \\
\hline Singers & 195.000 & 72.106 & .010 & 49.028 & 340.972 \\
\hline \multicolumn{6}{|l|}{ Sex } \\
\hline \multicolumn{6}{|l|}{ Female } \\
\hline Male & 331.667 & 160.210 & .043 & 10.972 & 652.361 \\
\hline
\end{tabular}

athletes and singers were also significantly different. Non-athletes non-singers had a significantly higher body mass index $(23.87 \pm 2.35 \mathrm{~kg} / \mathrm{m} 2)$ as compared to athletes $(20.66 \pm 1.52 \mathrm{~kg} /$ $\mathrm{m} 2)$ and singers $(22.6 \pm 1.84 \mathrm{~kg} / \mathrm{m} 2)$. Univariate linear regression demonstrated that male gender and height significantly affected lung capacity.

Conclusions In conclusion, encouraging regular exercise and singing in children improve vital capacity. Children are most susceptible to the harmful effects of air pollution. Opting for a healthy lifestyle may be an effective strategy to deal with the menace of air pollution.

\section{MONITORING ENDOTRACHEAL TUBE CUFF PRESSURES IN PAEDIATRIC CRITICAL CARE - ARE DANGEROUSLY HIGH PRESSURES GOING UNDETECTED?}

Rory Sweeney, Brendan Kelly, Christopher Flannigan. UK

\subsection{6/bmjpo-2021-RCPCH.60}

Background The use of cuffed endotracheal tubes (ETTs) in paediatric critical care has become widespread with the development of high volume - low pressure cuffs which require significantly lower sealing pressure than traditional ETTS. There remains a risk of over inflation which can impair tracheal capillary perfusion causing pressure necrosis of the surrounding fragile epithelium potentially resulting in permanent upper airway damage such as sub-glottic stenosis. Cuff pressure can vary over time therefore careful monitoring is vital to ensure the pressure remains within a safe range.

Objectives Connecting a manometer to the pilot balloon is one method to monitor cuff pressure. A prior study demonstrated that connecting a manometer caused a drop in pressure giving a falsely low readings. We hypothesised that pre- pressuring the manometer would result in accurate cuff pressure readings enabling detection of dangerously high pressures. Methods An airway model was intubated with Halyard size 3.0 micro-cuff ETT. Using a commercially available manometer, a three way tap and syringe the cuff was inflated to a set pressure in increments of $1 \mathrm{~cm} \mathrm{H} 2 \mathrm{O}$ between 0 and $40 \mathrm{~cm}$ $\mathrm{H} 2 \mathrm{O}$. The manometer was then connected to the pilot balloon to check the pressure using 3 methods:

Control 1) Manometer connected directly to the pilot balloon (no tubing used therefore pressure in the system $=0 \mathrm{~cm}$ $\mathrm{H} 2 \mathrm{O})$

Control 2) Manometer connected to the pilot balloon via extension tubing with 3 way tap and syringe in circuit (pressure in tubing and manometer system $=0 \mathrm{~cm} \mathrm{H2O}$ )

Test 3) Manometer connected to the pilot balloon via extension cable with 3 way tap and syringe in circuit with the entire circuit pre-pressurised to $20 \mathrm{cmH} 2 \mathrm{O}$ before connecting

Set-up 2) was used as a control to show how the tubing and 3 way tap affected the readings. For each method three measurements were performed at every $1 \mathrm{~cm} \mathrm{H} 2 \mathrm{O}$ increment and the average reading was taken.

Results Using method 1 the average manometer reading was significantly lower than the pre-set cuff pressure for example preset pressures of $20 \& 40 \mathrm{~cm} \mathrm{H} 2 \mathrm{O}$ read only 5.3 and $8 \mathrm{~cm}$ $\mathrm{H} 2 \mathrm{O}$ respectively. Using method 2 the average readings dropped even further from the pre-set pressure. Using method 3 with the manometer pre-pressurised to $20 \mathrm{~cm} \mathrm{H} 2 \mathrm{O}$ the reading dropped if the cuff pressure was $\leq 19 \mathrm{~cm} \mathrm{H} 2 \mathrm{O}$ and increased if the cuff pressure was $\geq 21 \mathrm{~cm} \mathrm{H} 2 \mathrm{O}$. A pre-set pressure of 0 gave a reading of $11 \mathrm{~cm} \mathrm{H} 2 \mathrm{O}, 10 \mathrm{read}$ as $17.7 \mathrm{~cm} \mathrm{H} 2 \mathrm{O}, 30 \mathrm{read}$ as 20 $\mathrm{cm} \mathrm{H} 2 \mathrm{O}$ and 40 read as $21.3 \mathrm{~cm} \mathrm{H} 2 \mathrm{O}$.

Conclusions The results indicate that the intervention of connecting a manometer renders the reading inaccurate. This disparity is due to the dead space in the manometer and also the tubing as shown by the lower readings from method 2 . The hypothesis of filling the dead space by pre-pressurising the manometer system did not result in more accurate readings as the pressure merely equalised across the system. Therefore the only way to ensure cuff pressures are not dangerously high is to deflate the cuff and use the 3-way tap system or cuff inflator to inflate to a safe pressure.

\section{ACTIONABLE PHARMACOGENETIC VARIANTS IN HONG KONG CHINESE EXOME DATA AND PROJECTED PRESCRIPTION IMPACT IN THE HONG KONG POPULATION LEADING TO PRECISION MEDICINE}

Mullin Yu, Brian Chung, Marcus Chan, Kit San Yeung, Clara Tang, Claudia Chung. Hong Kong

\subsection{6/bmjpo-2021-RCPCH.61}

Background Pharmacogenetics is the study of variability in drug response caused by genetic variations. It is estimated that 